\title{
What (and who) Works in Widening Participation? Supporting Direct Entrant Student Transitions to Higher Education.
}

Dr Maddie Breeze

School of Education, University of Strathclyde, Glasgow, UK

Mr Karl Johnson

Division of Psychology and Sociology, Queen Margaret University, East Lothian, UK

Dr Clare Uytman [corresponding author]

Division of Psychology and Sociology, Queen Margaret University, East Lothian, UK

Division of Psychology and Sociology, Queen Margaret University, Queen Margaret University Drive, Musselburgh, East Lothian, EH21 6EL, 0131474 0000, cuytman@qmu.ac.uk. 


\title{
What (and who) Works in Widening Participation? Supporting Direct Entrant Student Transitions to Higher Education.
}

\begin{abstract}
This article considers support programmes for direct entrant (DE) student transitions as a widening participation strategy. We reflect upon one induction and support project with 27 students transitioning from further education into the second year of undergraduate social science degree programmes in a Scottish university. We use focus group data to discuss what works (barriers to successful transitions, project successes and limitations) and primarily who works; how responsibility for supporting DE student transitions is distributed and which students benefit. Original findings confirm existing evidence that becoming an 'independent learner' is a challenge for DE students. However, analysis problematizes and significantly expands existing understandings of relationships with staff and peer support, and contributes new insight into how the materiality and everyday logistics of the university relate to DE student transitions. We argue for more institutionally embedded approaches to supporting student transitions, including resourcing academic staff to develop and provide this support.
\end{abstract}

Keywords: higher education; widening access and participation; student transitions; direct entrants. 


\section{Introduction}

Student transitions have received much attention in Scottish higher education (HE) for several years now. The QAA for Higher Education Scotland's 2014-2017 Student Transitions Enhancement Theme, developments in best practice (Christie and Johnson 2017), and a 2017 special issue of the Journal of Perspectives in Applied Academic Practice, evidence the proliferation of debates on student transitions in Scottish Universities. More broadly, research demonstrates the importance of student transitions to UK FE and HE (Kahu et al 2015; Meehan and Howells 2017; Pennington et al 2017). Transitions are typically understood linearly, according to an 'In-Through-Out' model, and metaphors of 'journeys' and life-cycles abound (Gordon et al 2016:7). However, transitions can be conceptualized non-linearly as 'a more complex, messy process' (ibid), including the recognition that ' ...direct entrants do not make seamless transitions to university' (Christie et al 2013: 635).

In this article we reflect upon a 2016-17 project designed to support a cohort of 27 direct entrant (DE) students transitioning from further education (FE) into the second year of four-year degree programmes in Psychology, Public Sociology, and Psychology and Sociology (joint honours) at Queen Margaret University, Edinburgh. The project sits at the juncture between student transitions and widening participation policy and practice. DE students incorporate various widening participation (WP) groups that are the focus of institutional and Governmental HE policies (Scot Gov 2016b). Definitions of 'widening participation groups' vary and can include 'women, lower socio-economic groups, mature adults, and ethnic minorities' (Tight 2012: 211). Likewise, DE students typically may be categorized under one or more of the following so-called 'nontraditional' groups: first-in-family into HE; minority ethnic; from a lower socioeconomic background, recorded as Social Index of Multiple Deprivation (SIMD) 
20/40 ${ }^{1}$; with a disability; mature students, and/or; have caring responsibilities (Roberts, 2011; Meharg et al., 2017). It is important then to attend to how student transitions relate to widening access, and Gordon et al. recommend 'considering how Student Transitions can be strategically aligned' with the Scottish Funding Council's (SFC) Commission on Widening Access (SFC 2016: 22).

Previous research evidences the challenges faced by DE students, upon transitioning from FE to HE (Morgan 2015), particularly around becoming 'independent learners' (Christie et al. 2013; Hockings et al. 2017). DE students encounter a new academic culture, including expectations that they arrive as already competent autonomous learners (Pike and Harrison 2011: 61-62). This literature informed our project, which we designed to support participants to develop skills for self-directed learning. Our DE student participants reported encountering similar challenges, and in this respect our findings align with existing understandings of barriers to successful DE transitions.

Significantly however, our findings and analysis allow us to problematize and expand upon existing understandings of three further aspects of supporting DE transitions. Existing evidence suggests that DE students experience university lecturers as more distant and less approachable compared to their FE teachers (HEA 2013; Meharg et al. 2017; Pike and Harrison 2011). Our findings echo this, and our project did generate opportunities for some academic staff to become more 'approachable'. However, drawing on our own experiences on the project we complicate the

\footnotetext{
${ }^{1}$ SIMD stands for Scottish Index of Multiple Deprivation and is the Scottish Government's
} official tool for identifying 'the most deprived areas in Scotland' (Scot Gov 2016a: 2). SIMD20 refers to an area that is in the ' $20 \%$ most deprived' of the data zones in Scotland. 
approachability of academics in the context of the devaluation of feminised 'pastoral' work and casualised working conditions in the accelerated academy (Vostal 2016).

Likewise previous research evidences the importance of peer support for DE transitions (Pike and Harrison 2011: 63-64). Our data indicates some of the limitations of peer support in practice, particularly when relying on often unpaid volunteer student mentors. Finally, we consider the barriers DE students face in adjusting to institutional structures and procedures (Roberts, 2011), and particularly how our data suggest that the everyday logistics and mundane materiality of the institution can be thought of as widening participation issues in the context of DE transitions.

The article begins with a discussion of relevant background and literature on widening participation in $\mathrm{HE}$ and the specificities of DE student transitions. We then provide an overview of our Widening Participation and Student Retention (WISeR) Direct Entrant Transitions (DET) project, its aims and scope, as informed by existing research evidence. Next, we consider our small-scale focus group methods. We discuss our findings according to four key themes: 1) academic skills and independent learning 2) complicating relationships with staff 3) complicating peer support 4) everyday logistics of higher education. Together these findings, in conversation with previous literatures, lead us to a discussion of which students benefit from initiatives such as ours, and how responsibility for supporting DE students is distributed among staff. Consequently, we argue for a more institutionally embedded, and sustainably resourced, approach to supporting DE student transitions.

\section{Background and literature}

Successive UK governments have produced policies seeking to address socio-economic inequality through social mobility and the supposedly meritocratic ethos of HE (Iannelli 2011; Tight 2012; Sosu et al. 2016; Rainford 2016a) and it is incumbent upon UK HEIs 
to widen access. Although it is clear that this 'is not simply about the admission of students from disadvantaged backgrounds' (Rainford 2016a: 45), policy is characterised by the assumption that students 'accessing' HE will complete their programme of study. In practice there are varying levels of engagement with widening participation among UK HEIs, beyond the production of access, or outcome, agreements (Sosu et al. 2016; Rainford 2016a; Tight 2012). Widening participation initiatives take place against the entrenched marketization of UK HE, where metrics of student satisfaction inform competitive recruitment of fee-paying students.

Here the case of a 'post 92' university in Scotland is particularly instructive. There are no tuition fees for Scottish domiciled students, and Scottish Funding Council (SFC) funding is tied to the recruitment and retention of students from widening participation groups, particularly those from areas of 'multiple deprivation'. This highlights class among intersecting forms of HE exclusions, and creates a specific widening participation agenda for 'post 92' institutions, for whom SFC funding provides a greater proportion of their income compared to their 'ancient' counterparts. Although the Scottish Government envisages all 19 of Scotland's HE institutions working to widening participation (Scot Gov 2016b: 2) analyses identify the reality of a two-tier approach (Ianelli, 2011; Christie et al 2013; Gallacher, 2014 and see SFC 2017b). While numerous progression paths are available for students to transition from FE onto university degrees (Gallacher 2014; Raffe and Croxford 2015; Sosu et al. 2016), in practice '[s]tudents who move to university directly from college are overrepresented' in 'post-92' HEIs (Christie et al 2013, p.625).

Moreover, the intersecting 'inequality regimes' that higher education reproduces are well established (Acker 2006). While universities make 'symbolic commitments' to inclusion and diversity, these have been interpreted as 'non-performative' in that they 
do not bring about what they name (Ahmed 2012, 2017; Taylor 2012). As with other students from 'non-traditional' backgrounds DE students encounter the institutional inequalities of universities (Waller et al 2018), where a white and middle class student body has existed as the unmarked norm for generations, and do so while joining 'cohorts of students who are already familiar with the HE environment' (Knox 2005: 103). Given this background, it is unsurprising that existing research highlights the barriers encountered by DE students, and reveals that on-going transition support is required, rather than the simple provision of places and funding (Morgan 2015; Penketh and Goddard 2008; Pike and Harrison 2011).

The significant differences between FE and HE learning (Morgan 2015: 108) mean that DE students are expected to adapt to a new academic culture (Pike and Harrison 2011: 55) that emphasizes self-reliance and independent learning (Christie et al 2013; Hockings et al., 2017). Learning new skills and keeping up with the workload (Tait \& Godfrey, 2001) is a challenge in this context where students can encounter expectations that they arrive as fully formed autonomous learners (Pike and Harrison 2011: 61-62). Becoming independent is a key theme of youth transitions research (Breeze et al 2017) and is central to DE transitions; 'successful transitions depend on the students becoming independent learners' (Christie et al. 2013: 623). As such, we designed our DET project to investigate students' need for, and support the development of, skills for autonomous learning.

The challenge of becoming an independent learner is exacerbated by (students' perceptions that they face) more distant and less approachable staff and a related lack of information about their new programmes and institutional procedures (HEA 2013; Pike and Harrison 2011; Meharg et al. 2017; Roberts, 2011). Together these issues can inform students' concerns about their academic ability, a sense that they are always 
'running to catch up' (ibid), and feelings of 'not being good enough' and 'not fitting in' (Morgan 2015: 108). To address these barriers existing research and evaluations recommends 'building prior relationships between university staff and [DE] students' (Morgan 2015: 108) and emphasises the importance of peer groups and mutual support (Pike and Harrison 2011: 63-64). To these ends, Knox (2005:103) describes the benefits of a preparatory module for preparing DE students 'for life at university and to help them acquire the necessary key skills for coping with HE delivery and assessment regimes'. This perspective is supported by Tait and Godfrey's (2001: 259) case study of a pre-semester credit bearing 'bridging module', which familiarized DE students with teaching and assessment methods and provided opportunities to develop independent study skills. Together these existing findings informed our DE transitions project, described in more detail below,

In existing research there is a risk of individualising DE transitions, focusing for instance on student 'choice' although rational choice models offer only a limited explanation of student transitions (Hoelscher et al 2008). Such an approach can place the responsibility for a 'successful' transition on the individual, who is expected to 'adapt' to new and unfamiliar 'academic culture' (Pike and Harrison 2011: 55). Like much within the neoliberal, 'entrepreneurial' (Taylor 2014) and 'performative' (Pereira 2017) university, this reminds us of the need to resist individual solutions to structural problems, and that 'widening participation initiatives need to engage with - and beyond - such interpersonal positioning in order to erode continued structured inequalities.' (Taylor 2008: 155).

Research that takes a Bourdieusian approach offers a set of conceptual tools for avoiding overly individualistic accounts of widening participation. For instance, Rainford (2016b) draws on the idea of an institutional doxa in HE, which informs who 
is recognised as a potential student, those who do not recognisably fit into such an institutional ideal type are then framed as deficient, and as responsible for adapting to the dominant academic culture. Research that operationalizes habitus (Bourdieu 1983, 1993) to understand working class students' sense - and lack - of belonging (Reay et al 2009; Abrahams 2017; Abrahams and Ingram 2013) shows how 'non-traditional' students can be seen as 'fish out of water' (Tranter 2003) or 'cultural outsiders' (Lehmann 2013: 2) in the middle class university. Taken together, this body of work points to the importance of understanding DE transitions as socially structured, and irreducible to individual-level phenomena. We therefore follow Rainford's (ibid) argument for shifting the locus of responsibility from the individual to the institutional level, and asking how universities can better adapt to the needs of DE students in transition.

\section{The project: direct entrant student induction}

In the spring semester of 2016 the authors were awarded internal Widening Participation and Student Retention (WISeR) funds ${ }^{2}$ to develop a small induction and retention initiative for DE students in the Division of Psychology and Sociology as they transitioned from HND courses at local colleges into the second year of our degree programmes. The project was designed, based on a previously successful programme from colleagues in our own Business and Management school, as a tailored longitudinal support programme and was run with a cohort of $27 \mathrm{DE}$ students joining the university in September 2016. Induction, and pre-induction, are critical stages for

\footnotetext{
${ }^{2}$ These funds are available via internal competition as part of the University's Outcome Agreement with the Scottish Funding Council.
} 
DE students, representing their 'first taste' of university life.

Overall, the project aimed to foster a sense of belonging to the university and to the Division of Psychology and Sociology. Specifically the project was designed to: provide programme-specific information and support; to support students in their development of key academic skills and independent learning; to foster the formation of peer and mutual support networks and enable new DE students to meet core-teaching staff in more 'approachable' settings during induction week and throughout their first semester at university. In this way, we aimed to put into practice existing evidence and recommendations from the widening participation and student transitions literatures.

In pursuit of these aims, the project comprised two related stages. Firstly, a 'selfdiagnostic' welcome quiz incorporating immediate tailored video feedback, to explore students' expectations of university and their perceptions of their strengths and needs during transition, and to deliver key information and signpost further resources. Secondly, and drawing on students' self-reported needs and expectations gathered via the welcome quiz, we designed and delivered a series of four tailored workshops, which ran throughout the first semester. Our project was imbedded in broader generic and programme-specific induction week activities, which included sessions on key skills for Psychology and Sociology, essay and assignment writing, and a lecture introducing research methods ${ }^{3}$. These combined approaches allowed the three of us to begin to get to know the students, and for them to get to know us, as soon as possible, and this continued as the authors convened and taught core second year modules across the division.

\footnotetext{
${ }^{3}$ Each of these topics were identified as likely to cause concerns for DE students, based on student feedback and course evaluations from previous years.
} 


\section{The welcome quiz}

A new section of our virtual learning environment (VLE) was set-up, with the help of our in-house learning and teaching technology expert, to host a 'welcome quiz' for the DE students, which we ran during their induction week in September 2016. Firstly, a welcome screen introduced students to key members of staff using images and text (Figure 1). This was intended to provide more informal introductions to staff than students would necessarily encounter. Students progressed through a series of multiplechoice 'anticipation' questions about expectations of university and any areas of concern, tailored to degree programme. This aspect of the quiz allows students to practice using the VLE, while allowing us to understand some of their perspectives on their transition to university.

The quiz continued with sections on general academic and discipline-specific study skills, and quiz questions were designed based on previous student evaluations and feedback and included items on 'perceived preparedness' for university. Based on students' responses, the quiz directed participants to an automatically released, tailored feedback video, featuring the authors and other core teaching staff speaking to camera in response to students self-reported levels of preparation and any concerns raised. Increasingly, video feedback is being explored in learning and teaching, as a means of encouraging engagement and of breaking down barriers between staff and students (Crook et al. 2012; Jones \& Sze Lau 2010; Thompson \& Lee, 2012).

Students were invited to complete the quiz in a computer lab in a scheduled session on the final day of induction week. This allowed the authors to be present in the room with students, to chat informally and answer any questions prompted by the quiz. In practice we found that students were keen to discuss the induction week as a whole, we could then attend to any gaps and outstanding issues they reported. This was 
consistent with our aim to present ourselves as approachable and available to respond to DE students' questions and concerns.

\section{[Figure 1]}

\section{The Workshops}

The project's second phase, a series of tailored workshops throughout the semester, drew upon DE student evaluations of induction week, our informal conversations with the DE cohort during the first weeks of semester, and our analysis of student responses to the welcome quiz. This allowed us to develop the workshop sessions on: how to access support services; an informal Q\&A drop in session with core teaching staff; presentation skills and confidence; and making the most of assessment feedback. By focusing these sessions, we hoped to directly address students' key areas of concern and maximise the benefit they were likely to experience from participation. The workshop sessions were non-compulsory, although students were encouraged to attend via in-class announcements and via email.

\section{Methods}

In January 2017, as we began to reflect upon the project, we invited students to participate in a focus group to discuss their experiences of the project and their first semester. The call for participants was sent via email to DE students and resulted in a group of four students, facilitated by two of the authors. While not intended as a representative sample, our four participants did reflect the cohort; one man and three women, one of whom was a mature student. The session lasted two hours and was audio-recorded and transcribed for thematic coding and analysis. While these students' 
transitions are in no way 'complete', our analysis offers a snap-short at a 'critical moment' (Thompson et al 2002) in their HE transitions.

The focus group was granted approval by the university research ethics committee, followed standard ethical procedures for small-scale qualitative research, and students provided verbal informed consent after being informed of procedures for anonymity and confidentiality. The focus group schedule was designed to generate indepth qualitative data about participants' experiences, in order to further explore the needs of DE students and how universities can support DE student transitions. Selfselection into focus group participation raises broader questions about whether the students we interacted with most were likely to be those who were struggling more with transition, or conversely those who were more experienced at engaging with staff and formal support structures. We return to these questions below.

Our analysis and discussion are based on a very small and self-selecting sample, situated in a post-92 university in Scotland, as well as in the disciplinary context of Psychology and Sociology. Our findings are informed by reflections on our experiences working on the project and by student evaluations, but primarily draw on analysis of the focus group transcripts. While students' responses to the welcome quiz informed the subsequent approach to workshop topics, the quiz was not designed to gather data for analysis and we did not seek ethical clearance to use the quiz responses as research data for publication.

Our findings are not representative of DE student transitions more broadly and are not intended to be generalizable beyond this local context. However, we join those who demonstrate the value of smaller-scale 'case study' qualitative research (Gerring 2004; Yin 1994) and propose that our study is significant in that it joins on-going debates on DE student transitions and how to best support students through this vitally 
important stage. As academics with research interests in HE inequalities, and as WP practitioners, we learnt from our experiences working on this project, and hope that our reflections can be useful to others. We offer our evidence and analysis then as a small but useful contribution to a much broader and cumulative body of knowledge.

\section{Findings and Discussion}

Focus group participants reported a range of positive experiences of direct entry, although these were discussed alongside considerations of 'dropping out' and not feeling 'good enough' to be at university. Analysis drew our attention to key themes in the challenges DE students face. In some respects, our analysis lends support to existing research findings, particularly in regard to the challenge of 'independent learning'. Additionally, our analysis extends and complicates this existing body of knowledge and enables us to significantly expand understandings of relationships with staff, and the role peer support in DE transitions, as well as contributing new insight into everyday HE 'logistics' as an important area for widening participation and student transitions practice.

\section{Academic Skills and Independent Learning}

Focus group participants repeated concerns in the literature with how different university was to their FE experiences. This was exacerbated by uncertainty around what to expect, and what was expected of them as independent learners. The university lecture was a feature of participants' accounts, including concerns over how to $d o$ university learning: how to take notes, what 'proper' behaviour in lectures looked like, and how to write and reference university essays: 
...after the induction week I was still like, I don't know what to fully expect, I know in theory, but not in practice, like how do you take notes and things like that? (participant 3)

Discussion included the challenges of using academic journal articles rather than the textbooks participants were accustomed to, including practical difficulties in accessing journal articles alongside the challenge of reading original research articles. HEA survey data suggests that college students across Scotland view university as intellectually challenging, and "intimidating" (2013: 3). Our analysis aligns with existing findings (Christie et al 2013; Hockings et al., 2017) on the challenge of transitioning to more independent and autonomous learning:

....at college it was very much like... we could stop the entire lecture to ask questions like, the whole way through the year, whereas coming in, and all of the lecturers have really different styles here compared to what we were used to at college, so kind of learning how to take notes, with the different people is really difficult, I still struggle with that to be honest. (participant 2)

Having achieved high grades at college for their written work - indeed having been addressed as exceptional students, eligible for direct entry into second year of university - participants were surprised and worried when their university grades were lower than their expectations. Participants described exceedingly detailed guidance for their college assessments, 'you've got to hit this point, this point, this point, but it really is broken right down' (participant 2) and contrasted this to expectations at university to synthesise information and develop an argument: 'whereas here it's much more like, take it on your own, and critically evaluate, and just go for it really' (participant 2).

Focus group participants suggested that more practical experience of being at university would have offered greater benefit compared to the 'induction' programmes, especially in terms of transitioning to more autonomous learning. This included the idea 
of holding a DE student 'summer school' prior to semester start, which could feature 'mock' lectures and assessments, offering more hands-on preparation than the advice and information provided via induction. This lends support to the research findings discussed above that emphasise the importance of 'bridging' and preparatory presemester modules (Knox, 2005; Tait and Godfrey 2001).

Participants also reported instances of missing out on substantive course content, when lecturers referred to first year modules, which DE students had not participated in:

... there's a lot of 'oh yeah we're not going to cover this because you did it last year' and I was sat there going, 'yeah no we didn't, I have no idea what you're talking about right now' (participant 1)

Such references to first year course content were destabilising for these DE students, feeling like they were missing out on important content and as if their presence wasn't recognised or taken into account by lecturers, perceived to be lecturing for students who had completed first year.

This first analytical theme aligns with existing research, which emphasizes how DE students encounter university as significantly different from FE, particularly according to the expectation that students learn 'independently'. University here is also a context in which their 'WP' and 'DE' status marks participants as somewhat other. Being reminded of their DE status, for example through references to first year content as assumed common knowledge, contributed to a sense of deficiency in skills and knowledge that appeared to come naturally to already-attending students.

\section{Complicating Relations with Staff}

Focus group data aligns with existing findings that students perceive university teaching staff as more distant and less approachable (Meharg et al. 2017; Pike and Harrison 
2011). This was particularly visible as students described a reluctance to ask for help:

People are scared to come and see you [lecturers] because then you'll know they're not coping. Like, 'if I make it look like I can't do this then they're going to kick me out'. (participant 2)

...we only had three lecturers at college, so we had the same person the whole way through, we got to know their style from the beginning, and it was really easy to ask them questions, or say if you didn't understand. (participant 1)

Confronted with more teaching staff, and fearing being seen not to 'cope', these DE students felt it was more difficult to 'get to know' different lecturers and different lecturing styles, and to approach staff with questions. This aligns with findings from the HEA (2013) study that FE students were concerned that university lecturers would be more 'stand-offish'.

Our project did generate opportunities for DE students to familiarize themselves with key members of teaching staff using video feedback and the informality of our workshop sessions with them. Likewise, our university is a small institution ${ }^{4}$, and the authors often bumped into DE students in the corridors, in the canteen, and taught them on core modules. Becoming some of the faces that students recognized, and in some cases, being able to offer guidance, was a gratifying part of our work on this project. However, this was accompanied by the observation that some staff were more likely to be approached than others. Getting to know lecturers is something that often occurs in the informal spaces of HE, chatting before and after classes. This diffuse process is not something that is easily quantified or accounted for in WP budgets, nor is it something that it is particularly easy to make space for in 'fast academia' (Gill 2010: 9). We can further situate these experiences in relation to evidence on the distribution of 'academic

\footnotetext{
${ }^{4}$ HESA statistics report 3655 undergraduate students in 2015/16.
} 
housework' (Heijstra et al. 2017); feminised labour that is unlikely to be institutionally recognised or rewarded (Morely 2013).

\section{Complicating Peer Support}

Existing research recommends peer support as beneficial for student transitions:

The establishment of peer mentors or 'buddies'... would provide a familiar face, help demystify the academic culture and expectations of the HEI, and promote integration. It might also help progressing students to feel less isolated (Pike and Harrison 2011: 63-64)

Participants did report the benefits of forming mutually supportive relationships amongst their DE cohort, particularly in sharing concerns and realizing that they 'were not alone'. Likewise, DE students were accompanied by a third year student volunteer, or 'student ambassador', during their induction week, and we were interested in finding out about students' experiences of this peer support initiative. Our data invites some critical pause on the topic of peer support, and paints a more complicated picture:

I think that at that point, for me certainly I felt like the person who was trying to help... was not having a great experience, that's just how I felt. (participant 1)

I know what I remember... being told that if I put a comma in the wrong place that I would lose like $40 \%$ of the mark (participant 3 )

Here participants discuss an alarming inaccuracy passed to them during induction week that minor grammar mistakes would lead to failing essays. This understandably caused a great deal of worry, and the misinformation spread quickly. A related example discussed in the focus group involved a peer who told of writing an ' $A$ ' grade essay in a mere two hours, leading to unrealistic expectations and compounded self-doubt for 
some DE students.

Our intention in including these quotes is neither to dismiss the important role of peer support, nor to single-out these instances of unhelpful 'advice' from fellow students, which may have been well intentioned. We offer this discussion instead as a contribution to understanding how support mechanisms for DE transitions cannot be understood reductively only in terms of 'positive' and 'beneficial' effects. While peer support mechanisms can help 'demystify' the new HE culture and expectations, it is important to ask whether student volunteers, who may not be adequately supported themselves, are best placed to do this work, which is arguably a responsibility of the institution. This leads on to our final theme; DE transitions in the context of the everyday logistics of university life.

\section{Everyday logistics of higher education}

We were struck by the centrality of procedural day-to-day aspects of university life to participants' discussion, given the relative absence of these issues in the literature. Being unfamiliar with the layout of the university building, with how different floors and rooms were numbered and how to find them, was noted as not only confusing and frustrating, but as connected to feelings of not-belonging and not being able to cope. Similarly, frustrating for some participants were problems with timetabling, characterized by changes in their class schedules, clashes, and being provided with different versions of their timetable, and this connected to feeling unsure about their place in the institution.

I didn't want to come in and go 'I don't even know where a room is' never mind when you've got students running about. (participant 3 ) 
I know [now] there's a student services, but that wasn't really anything that anyone explained to us, although I just might not have been there, but yeah I had no idea that there was stuff like that that we could go and access. (participant 1)

Well we didn't really, we were shown to rooms, like go this way for your lecture, like the one for your induction, but we weren't shown round the building. (participant 3)

Similar concerns clustered around assessment submission procedures:

A lot of things like the dropboxes [for essay submission], they were described [in induction week] but they weren't actually shown, and 'well they're just round there', everyone was like 'oh right, so it's roughly here'... I remember about turnitin $^{5}$, we were always told about it at college but we were never shown... and if we were shown how to put that in, that would be a lot more useful... to be more confident to actually submit... (participant 4)

Prior to the focus group, we didn't appreciate the significance that these moments had for DE students, and how their significance went beyond the immediate - and addressable - frustrations of temporarily not knowing how to find rooms or submit assignments. There is a risk that those already habituated to the institution might not fully appreciate the weight of such issues. For these students, uncertainty around the practical logistics of university life exacerbated their felt out-of-place-ness, and underscored their status as new, and as not-knowing how the university worked. In participants' accounts, uncertainty around seemingly small and mundane issues was related to much broader uncertainties, around their place in the institution.

These insights from the focus group data led us to reconsider our conceptions of what counted as a WP issue, and to question whether DE transitions support can be

\footnotetext{
${ }^{5}$ Turnitin is an online plagiarism checker used by students and staff for checking and submitting assignments.
} 
considered more broadly. When the bureaucratic systems (how to submit assignments, timetabling) and materiality of the institution (room signposting, building layout) are imagined as widening participation work, we are challenged to develop a more holistically and institutionally embedded approach. These observations, together with our experience on the project, enable us to raise two critical questions: about which students are positioned to benefit from DE transitions projects such as ours, as well as which staff are most likely to do the work of supporting DE transitions. These questions frame our concluding recommendations, which centre on the case for embedded support for DE students and a more institutional-level approach to widening participation.

\section{Which students?}

We were prompted to consider this question in part by lower than expected attendance at our non-compulsory workshop sessions. The focus group participants, and DE cohort more broadly, expressed that while they appreciated the workshops, they were often unable to attend due to timetabling issues and other commitments, including assessments and coursework but also those outside the university such as caring responsibilities and paid work. Participants had little free time outside of their compulsory credit-bearing university study, and this was compounded by the time that adjusting to university life took up in their schedules. Just as WP programmes more broadly can be criticized for selectively picking the most 'deserving' students (Rainford 2016: 47) we wonder if those students who would potentially benefit most from our project were tacitly excluded. This led us to think that embedding our targeted support sessions as core content in credit-bearing modules might mediate against this issue.

Our experiences provoked us to think about the potentially counter-productive consequences of addressing DE students as a distinct group, with a set of clear needs assumed to arise as a consequence of their DE status. We were struck by the sense that 
many of the issues that DE students faced were likely also experienced by their non-DE peers, who we suspected may also benefit from many aspects of the project. These hunches are born out in research, where for instance a 'sense of belonging' is important for all students during transitions (Meehan and Howells 2017; Wilcox et al 2005). Christie et al (2013: 623) unpick the differences and similarities between DE and continuing student transitions: "The difficulties experienced by many new students... may be exacerbated amongst direct entrants because they have less time in which to adapt to the new regime and their needs are often less visible at the institutional level." This points us to how the challenges of transition may be 'sharper' for DE students, but primarily due to institutional factors - a compressed time period for transition and a lack of institutional visibility - rather than any inherent characteristic of DE students themselves. Research with the 'new student' characteristic of post-92 universities highlights similarities including students' concerns about the 'perceived need to be an independent learner' and the need for 'more support from academic staff, with clear instructions about what was expected' (Leese 2010: 239; Pennington et al 2017; Briggs et al 2012). DE students experience challenges that are shared by other students, particularly in the context of a post-92 university.

This raises the possibility that targeted support for DE students may unnecessarily single these students out from peers they are already positioned as somewhat other to. Writing this article, like the project as a whole, has therefore involved negotiating tensions between our aim to understand what universities can do to better support DE students, and attempting to avoid labelling DE students as 'deficient'. We are wary of how well-intentioned WP initiatives 'can in fact reproduce inequalities' (Rainford 2016: 45) and our findings lend support to the argument for the 
standardization of approaches to induction, across all student groups, (Jones, 2008;

Christie \& Johnson, 2017; Thomas et al., 2017).

\section{Which staff?}

In advocating for the standardisation and embedding of student transitions support, the issue of who does this work comes to the fore. In the case of our project, internal funds paid for each of the three authors to work on the project for half a day per week for approximately nine months. If we hadn't successfully bid for this funding, then the project would not have taken place. The funding cycle for WISeR projects is short term, with funding opportunities advertised, and funds available once a year. The funding parameters stipulate how projects must be complete before the end of the financial year, leaving nine months for project completion. This limits the sustainability of projects, especially the extent to which they can be meaningfully embedded or long-term. Particularly with relatively small student cohorts, gathering of statistically significant data on the effectiveness of these projects is compromised (Younger et al 2018).

While some support mechanisms are codified in job role descriptions and workload allocations and included in the remit of widening participation committees, others take place in the informal spaces between classes, in inboxes at evenings and weekends. Informal support can be contingent upon the availability and 'goodwill' of individual staff; unevenly distributed and institutionally unrewarded academic 'housework' (Heijstra et al 2017). As 'early career' academics employed on part time and temporary contracts, the time and energy we could devote in the long term was limited. Yet we often worked more than the hours we were paid for on this project, doing unpaid work as part of the core business of the university (Wånggren 2018).

While small scale initiatives for supporting DE transitions can have positive outcomes (for instance, staff may become less distant and more approachable), this 
effectiveness is limited by a dependence on staff 'goodwill' and associated dependence on institutionally unrecognised (often unpaid, feminized) labour of (often casualised) staff. Such initiatives are also unlikely to generate the kind of robust empirical evidence necessary for effective evaluation, and are therefore likely to remain unfunded and unrecognized despite official institutional commitments to widening participation.

\section{Conclusion}

In some respects, our analysis lends support to existing findings, particularly in regard to the challenges experienced by DE students around adjusting to a new academic culture (Pike and Harrison 2011: 55) that emphasizes self-reliance and independent learning (Christie et al 2013; Hockings et al., 2017). While our project did aim to support students through this adjustment, we follow others in questioning this frame which positions DE students as deficient and responsible for adapting to the institution (Rainford 2016b). Our findings and analysis also problematize and significantly expand existing understandings of relationships with staff and peer support, both of which can suffer from a lack of sustainable resourcing and perpetuate individualistic understandings of widening participation. Finally, our research contributes new insight into how the materiality and everyday logistics of the university relate to DE student transitions, and can be thought of an important area for widening participation practice.

These last two themes in particular prompted us to ask which students are likely to benefit from projects such as ours, and which staff are likely to do the work of supporting student transitions. Here we saw that different levels of engagement with our project, and how 'targeting' DE students, can re-inscribe a disjuncture between their habitus and the institution. Likewise, we observed how the work of supporting DE student transitions was unevenly distributed and not always recognised or rewarded by 
the institution, and this can be exacerbated by short-term and unsustainable funding structures.

Our experience and analysis accords with Rainford's (2016a: 45) suggestion that the work of widening participation should go 'far beyond those departments tasked with access and outreach and has implications for staff across all academic and support service areas'. This leads us to conclude that support for DE transitions should be thoroughly embedded in HEIs. Ways that this could be pursued include: 1) improved training for student volunteers and peer mentors, in order to reduce the spread of inaccurate and worrying information; 2) improved awareness among lecturers about DE needs, including unfamiliarity with first year course content; 3) standardised, and sustainably funded, transitions support, to address the common concerns of DE and continuing students; 4) consider institutional policies to 'mainstream' widening participation, mandating the consideration of the WP implications of all aspects of the university as institution, in order to reduce the exclusionary effects of the logistics of university life.

We have seen how a problem with the benefits of informal support is that this work is not easily recognized in workload allocations or rewarded via pay and promotions. As such our experience points to a need for an element of formalising recognising the value of - the informal, in job role descriptions for instance, so that staff can be adequately remunerated for this vital work. Likewise, changes at the level of funding structures - more funds and a longer cycle - would enable more sustainable project development, the gathering of more reliable evidence on effectiveness, and more meaningfully longitudinal support for student transitions.

\section{Acknowledgments}


Sincere thanks to Denny Roberts (Centre for Academic Practice, QMU) for his invaluable support, expertise, guidance and patience as well as to our brilliant students. Thanks also to the WISeR board for funding the project.

\section{References}

Abrahams, J. 2017. Honourable mobility or shameless entitlement? Habitus and graduate employment. British Journal of Sociology of Education 38 (5): 625640.

Abrahams, J., and N, Ingram. 2013. "The Chameleon Habitus: Exploring Local Students' Negotiations of Multiple Fields." Sociological Research Online 18 (4): 21. http://www.socresonline.org.uk/18/4/21.html

Ahmed, S. 2012. On Being Included: Racism and Diversity in Institutional Life. North Carolina: Duke University Press.

Ahmed, S. 2017. Living a Feminist Life. North Carolina: Duke University Press.

Alexander, R. 2016. "Migration, education and employment: socio-cultural factors in shaping individual decisions and economic outcomes in Orkney and Shetland." Island Studies Journal 11 (1): 177-192.

Bourdieu, P. 1984. Distinction: A Social Critique of the Judgement of Taste. Cambridge: Harvard University Press.

Bourdieu, P. 1993. The Field of Cultural Production: Essays on Art and Literature. Cambridge: Polity Press.

Breeze, M., H. Gorringe, L. Jamieson, and M. Rosie. 2017. "Becoming independent: political participation and youth transitions in the Scottish referendum." British Journal of Sociology 68 (4): 754-774.

Briggs, A.R.J., J. Clark, and I. Hall. 2012. "Building bridges: understanding student transition to university." Quality in Higher Education 18 (1): 3-21.

Christie, H., P. Barron, and N. D'Annunzio-Green. 2013. "Direct entrants in transition: becoming independent learners.” Studies in Higher Education 38 (4): 623-637.

Christie, H., and K. Johnson. 2017. "Don't Panic: Common Sense and the Student Voice in a Transitional Guide." Journal of Perspectives in Applied Academic Practice 5 (2): 66-72. 
Crook, A., A. Mauchline, C. Lawson, R. Drinkwater, K. Lundqvist, P. Orsmond, S. Gomez, and J. Park. 2012. "The use of video technology for providing feedback to students: Can it enhance the feedback experience for staff and students?" Computers \& Education 58: 386-396.

Enhancement Themes. 2014. Current Enhancement Theme. Quality Assurance Agency for Higher Education. Accessed 10 August 2017. http://www.enhancementthemes.ac.uk/enhancement-themes/currentenhancement-theme

Evans, C. 2017. "Framing young people's educational transitions: the role of local and contemporary economic contexts." British Journal of Sociology of Education 38 (35): 656-670.

Gallacher, J. 2014. "Higher education in Scotland: differentiation and diversion? The impact of college-university progression links." International Journal of Lifelong Education 55 (1): 96-106.

Gerring, J. 2004. "What is a case study and what is it good for?" The American Political Science Review 98 (2): 341-354.

Gill, R. 2010. "Breaking the silence: The hidden injuries of neo-liberal academia." In Secrecy and Silence in the Research Process: Feminist Reflections, edited by R. Flood and R. Gill, 228-244. London: Routledge

Gordon, L., A. Dennis, D. Jindal-Snape, and S. Howden. 2016. Evaluation of Year 2 of the Student Transitions Enhancement Theme Evaluation Report. Glasgow: Quality Assurance Agency for Higher Education. http://www.enhancementthemes.ac.uk/docs/report/evaluation-of-year-2-of-the$\underline{\text { student-transitions-enhancement-theme.pdf?sfvrsn }=8}$

HEA. (2013). Learning Journeys: Student experiences in further and higher education in Scotland. Edinburgh: Higher Education Academy. Accessed 10 August 2017. https://www.heacademy.ac.uk/system/files/resources/learning_journeys_2013.p $\underline{\mathrm{df}}$

Heijstra, T.M., F. S. Steinthorsdóttir, and T. Einarsdóttir. 2017. "Academic career making and the double-edged role of academic housework." Gender and Education 29 (6): 764-780.

Hockings, C., L. Thomas, J. Ottaway, and R. Jones. 2017. "Independent learning - what we do when you're not there." Teaching in Higher Education 0 (0) 1-17. doi: 10.1080/13562517.2017.1332031. 
Hoelscher, M., G. Hayward, H. Ertl, and H. Dunbar-Goddet. 2008. "The transition from vocational education and training to higher education: a successful pathway?" Research Papers in Education 23 (2): 139-151.

Ianelli, C. 2011. "Educational Expansion and Social Mobility: The Scottish Case." Social Policy \& Society 10 (2): 251-264.

Jones, R. 2008. Student retention and success: a synthesis of research. Higher Education Academy. Accessed 10 August 2017. https://www.heacademy.ac.uk/system/files/wp_retention_synthesis_for_pdf_upd ated_090310_0.pdf

Jones, N., and A. M Sze Lau. 2010. "Blending learning: widening participation in higher education.” Innovations in Education and Teaching International 47 (4): 405-416.

Kahu, E., C. Stephens, L. Leach, and N. Zepke. 2015. "Linking academic emotions and student engagement: mature-aged distance students' transition to university." Journal of Further and Higher Education 39 (4): 481-497.

Knox, H. 2005. "Making the transition from further to higher education: the impact of a preparatory module on retention, progression and performance." Journal of Further and Higher Education 29 (2): 103-110.

Leathwood, C. 2004. "A Critique of Institutional Inequalities in Higher Education.” Theory and Research in Education 2 (1): 31-48.

Leese, M. 2010. "Bridging the gap: supporting student transitions into higher education." Journal of Further and Higher Education 34 (2): 239-251.

Lehmann, W. 2013. "Habitus Transformation and Hidden Injuries: Successful Workingclass University Students.” Sociology of Education 87 (1): 1-15.

Meehan, C., and K. Howells. 2017. “What really matters to freshers?': evaluation of first year student experience of transition into university." Journal of Further and Higher Education 0 (0): 1-15. doi: 10.1080/0309877X.2017.1323194.

Meharg, D., E. Taylor-Smith, A. Varey, C. Mooney, and S. Dallas. 2017. “An Enhanced Route from FE to HE Graduation?" Journal of Perspectives in Applied Academic Practice 5 (2): 85-92.

Morely, L. 2013. "The rules of the game: Women and the leaderist turn in higher education." Gender and Education 25 (1): 116-131. 
Morgan, J. 2015. "Foundation degree to honours degree: the transition experiences of students on an early years programme." Journal of Further and Higher Education 39 (1): 108-126.

Penketh, C., and G. Goddard. 2008. "Students in transition: mature women students moving from foundation degree to honours level 6." Research in PostCompulsory Education 13 (3): 315-27.

Pennington, C. R., E. A. Bates, L. K. Kaye, and L. T. Bolam. 2017. "Transitioning in higher education: an exploration of psychological and contextual factors affecting student satisfaction." Journal of Further and Higher Education 0 (0): 1-12. doi: 10.1080/0309877X.2017.1302563.

Pereira, M. 2017. Power, Knowledge and Feminist Scholarship: an Ethnography of Academia. London: Routledge.

Pike, A., and J. Harrison. 2011. "Crossing the FE/HE divide: the transition experiences of direct entrants at Level 6." Journal of Further and Higher Education 35 (1): $55-67$.

Raffe, D., and L. Croxford, L. 2015. "How stable is the stratification of higher education in England and Scotland?" British Journal of Sociology of Education 36 (2): 313-335.

Rainford, J. 2016a. "Targeting of widening participation measures by elite institutions: widening access or simply aiding recruitment?” Perspectives: Policy and Practice in Higher Education 21 (2-3): 45-50.

Rainford, J. 2016b 'How institutional doxa can shape choice within Higher Education', paper presentation at Understanding the contemporary higher education student, University of Surrey

Reay, D., G. Crozier, and J. Clayton. 2009. “'Strangers in Paradise’? Working-class Students in Elite Universities." Sociology 43 (6): 1103-1121.

Reay, D., G. Crozier, and J. Clayton. 2010. “'Fitting in' or 'standing out': working-class students in higher education." British Educational Research Journal 36 (1): 107124. 
Roberts, S. 2011. "Traditional practice for non-traditional students? Examining the role of pedagogy in higher education retention." Journal of Further and Higher Education 35 (2): 183-199.

Scottish Funding Council. 2016. Commission on Widening Access. Accessed 10 August 2017.

http://www.sfc.ac.uk/Priorities/Access/Cowa/CommissiononWideningAccess.as

px

Scottish Funding Council. 2017. Outcome Agreement Funding for Universities.

Accessed 10 August 2017. http://www.sfc.ac.uk/publicationsstatistics/announcements/announcements-2017/SFCAN092017.aspx

Scottish Government. 2016a. Introducing the Scottish Index of Multiple Deprivation. Accessed 22 December 2017. http://www.gov.scot/Resource/0050/00504809.pdf

Scottish Government. 2016b. A Blueprint for Fairness: The final report of the commission on widening access. Edinburgh: Scottish Government.

Sosu, E. M., L. N. Smith, S. McKendry, N. Santoro, and S. Ellis. 2016. Widening Access to Higher Education for Students from Economically Disadvantaged Backgrounds: What works and why? Glasgow: University of Strathclyde.

Tait, H., and H. Godfrey. 2001. "Enhancing the Student Experience for Direct Entrants to the Penultimate Year of Undergraduate Degree Programmes." Journal of Further and Higher Education 25 (2): 259-265.

Taylor, Y. 2008. "Good students, bad pupils: constructions of "aspiration", "disadvantage" and social class in undergraduate-led widening participation work." Educational Review 60 (2): 155-168.

Taylor, Y, ed. 2012. Educational Diversity: The subject of difference and different subjects. Basingstoke: Palgrave Macmillan.

Taylor, Y, ed. 2014. The Entrepreneurial University: Engaging Publics, Intersecting Impacts. Basingstoke: Palgrave Macmillan.

Thomas, L. 2012. Building student engagement and belonging in Higher Education at a time of change: final report from the What Works? Student Retention \& Success programme. Accessed 22 December 2017.

https://www.heacademy.ac.uk/system/files/what_works_final_report.pdf 
Thomas, L., M. Hill, J. O’Mahony, and M. Yorke. 2017. Supporting student success: strategies for institutional change. What Works? Student Retention \& Success programme Final Report. Higher Education Authority.

Thomson, R., R. Bell, J. Holland, S. Henderson, S. McGrellis, and S. Sharpe. 2002. "Critical moments: choice, chance and opportunity in young people's narratives of transition." Sociology 36 (2): 335-354.

Thompson, R., and M. J. Lee. 2012. "Talking with Students through Screencasting: Experimentations with Video Feedback to Improve Student Learning." The Journal of Interactive Technology \& Pedagogy 1 (Spring). https://jitp.commons.gc.cuny.edu/talking-with-students-through-screencastingexperimentations-with-video-feedback-to-improve-student-learning/

Tight, M. 2012. "Widening Participation: A Post-War Scorecard.” British Journal of Educational Studies 60 (3): 211-226.

Tranter, D. 2003. “"Fish out of Water": students from disadvantaged schools and the university experience.” Paper presented at Creating Spaces: interdisciplinary writings in the Social Sciences Conference, Australian National University, Canberra, July 17-18.

Vostal, F. (2016) Accelerating Academia: The Changing Structure of Academic Time Basingsroke: Palgrave Macmillan

Waller, P., N. Ingam, and M.R.M. Ward. 2018 Higher Education and Social Inequalities: University admissions, experiences and outcomes London Routledge

Wånggren, L. 2018. Feminist trade unionism and post-work imaginaries, Journal of Applied Social Theory

Wilcox, P., S. Winn, and M. Fyvie-Gauld. 2005. "'It was nothing to do with the university, it was just the people': the role of social support in the first-year experience of higher education." Studies in Higher Education 30 (6): 707-722.

Yin, R. K. 1994. Case Study Research: Design and Methods. 2nd ed. London: Sage.

Younger, K., L. Gascoine, V. Menzies, and C. Torgerson (2018) 'A systematic review of evidence on the effectiveness of interventions and strategies for widening participation in higher education', Journal of Further and Higher Education (early view) 
Figure 1:

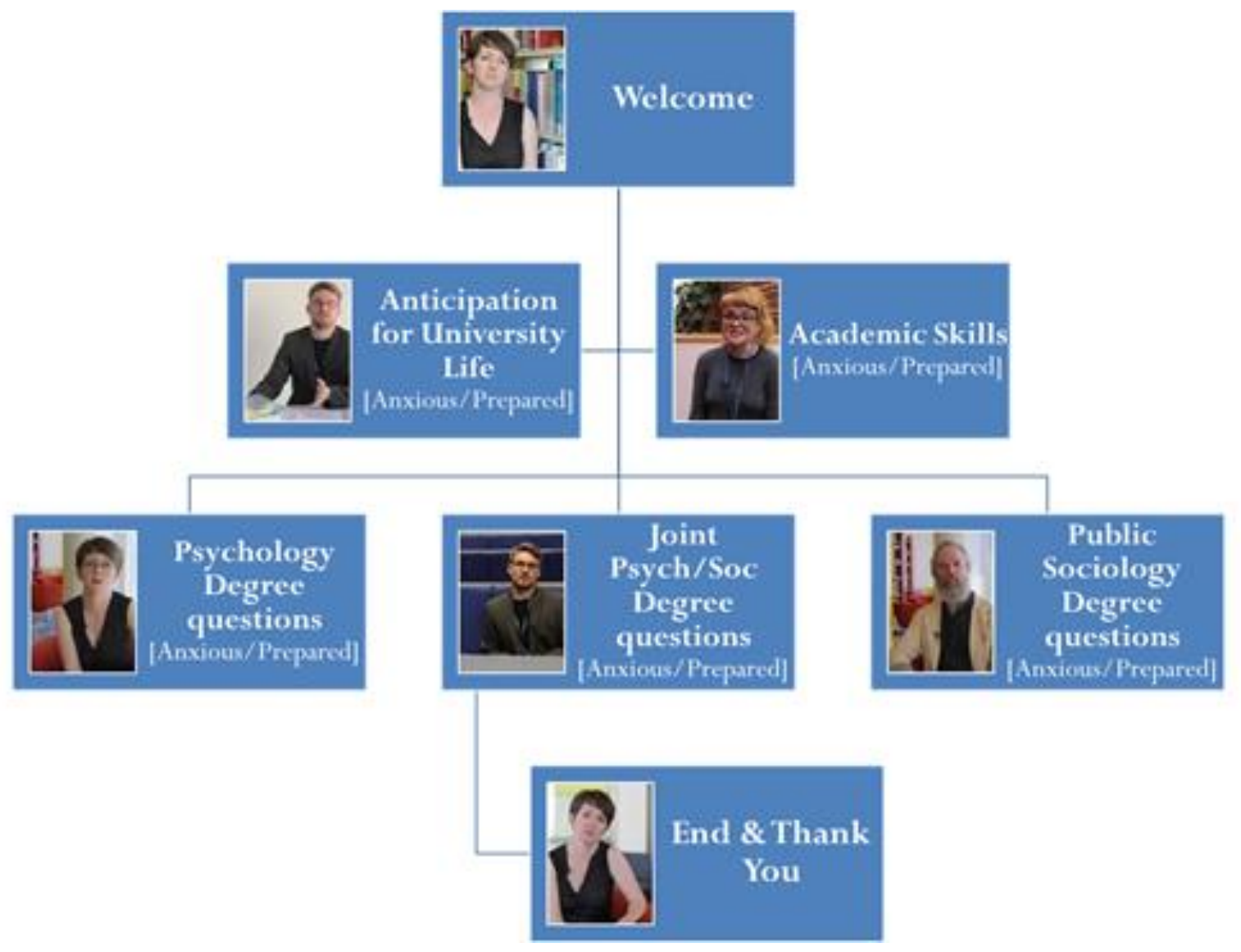

